\title{
Analysis and Design of the Interface Inductor and the DC Side Capacitor in a STATCOM with Phase and Amplitude Control Considering the Stability of the System
}

\author{
Guopeng Zhao ${ }^{\dagger}$, Minxiao Han*, and Jinjun Liu** \\ $\dagger^{*}$ School of Electrical and Electronic Engineering, North China Electric Power University, Beijing, China \\ ** School of Electrical Engineering, Xi'an Jiaotong University, Xi'an, China
}

\begin{abstract}
Previous publications regarding the design and specifications of the interface inductor and the DC side capacitor for a STATCOM usually deal with the interface inductor and the DC side capacitor only. They seldom pay attention to the influences of the interface inductor and capacitor on the performance of a STATCOM system. In this paper a detailed analysis of influence of the interface inductor and the DC side capacitor on a STATCOM system and the corresponding design considerations is presented. Phase and amplitude control is considered as the control strategy for the STATCOM. First, a model of a STATCOM system is carried out. Second, through frequency domain methods, such as transfer functions and Bode plots, the influence of the interface inductor and the DC side capacitor on the stability and filtering characteristics of the STATCOM are extensively investigated. Third, according to this analysis, the design considerations based on the phase margin for the interface inductor and the DC side capacitor are discussed, which leads to parameters that are different from those of the traditional design.
\end{abstract}

Key Words: DC side capacitor, Interface inductor, Phase and amplitude control, Phase margin, STATCOM

\section{INTRODUCTION}

A Static Synchronous Compensator (STATCOM) is one of the FACTS (flexible AC transmission system) devices. It is an advanced shunt compensator when compared with other compensators. A STATCOM can be utilized to regulate voltage, control power factor, stabilize power flow and improve the dynamic performance of power systems [1]. This compensator has been gaining wide attentions in recent years [2]-[5]. There is a voltage source converter connected to the grid through an interface inductor in a STATCOM system. The interface inductor is a low pass filter.

The design of the interface inductor and the DC side capacitor is very important. Many papers discuss the selection methods for the STATCOM parameters. For example, in [6], [7], the interface inductor must satisfy the ripple current requirement, and, in [8], the voltage drop across the inductor must be taken into consideration to design an interface inductor. The methods mentioned in these three papers are very useful for choosing

\footnotetext{
Manuscript received Mar. 11, 2011; revised Dec. 5, 2011

Recommended for publication by Associate Editor Kyo-Beum Lee.

$\dagger$ Corresponding Author: zhaoguopeng@ncepu.edu.cn

Tel: +86-10-80798443, Fax: +89-10-80798443, North China Electric Power University

* School of Electrical and Electronic Engineering, North China Electric Power University, China

** School of Electrical Engineering, Xi'an Jiaotong University, China
}

the parameters of an interface inductor. However, the stability of the STATCOM systems were not considered with any of the selection methods. In practical applications, the filtering performance is usually the main aspect considered. Then, by using the experience of practical applications and many experimental results, the parameters of the interface inductor are usually designed. In terms of the DC side capacitor, many papers reduce the DC side capacitor. For example, in [8] highly reliable film capacitors are used to minimize the capacitor size and cost. This paper also mentioned that the design approaches for the DC side capacitors often depend on three aspects: the maximum ripple current capability of the capacitor, the maximum allowable voltage ripple and the desired ride through capability during grid failures or voltage sags. The design approaches are valid. However, the stability of STATCOM systems should be considered when designing the DC side capacitor. In [9]-[11], methods to reduce the DC side capacitor were presented, and the minimum capacitor size was obtained. In [12]-[14], methods for reducing the voltage ripple to design the DC side capacitor were presented. Previous publications regarding the design and specifications of the interface inductor and the DC side capacitor for a STATCOM usually deal with the interface inductor and the DC side capacitor only, and seldom pay attention to the influences of the interface inductor and the DC side capacitor on STATCOM 


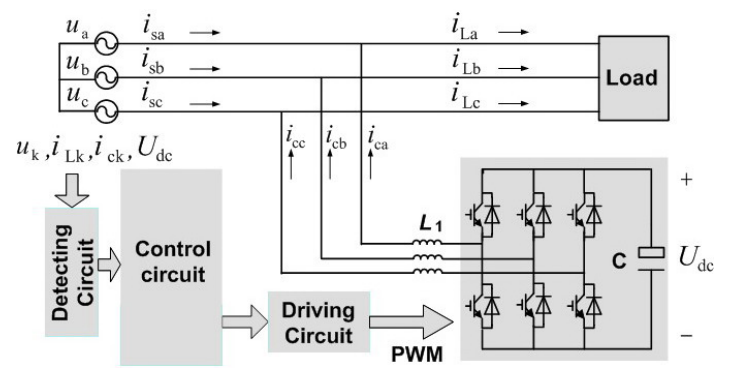

Fig. 1. Main circuit of the STATCOM.

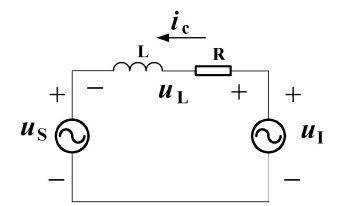

Fig. 2. Single-phase equivalent circuit.

system performance. However, this is not enough.

Therefore, the influence of the interface inductor and the DC side capacitor on the stability of a STATCOM system should be analyzed. Then, the interface inductor and the DC side capacitor can be designed more reasonably and more highly optimized.

In this paper a detailed analysis of the interface inductors and the DC side capacitors that influence STATCOM systems, and the corresponding design consideration are presented. In STATCOM systems, especially in high voltage and power situations, the interface inductor is usually an inductor, and two basic control methods are used. One is the phase-shift control [15]-[18], and the other is the Phase and Amplitude Control (PAC) [19]-[22]. In this paper, the phase and amplitude control is considered as the STATCOM control strategy. First, a model of the STATCOM is carried out. Second, the transfer functions are presented, and the influence of the interface inductor and the DC side capacitor on the STATCOM system stability and filtering characteristics are extensively investigated. Third, based on this analysis, the design considerations for the interface inductor and the DC side capacitor are presented.

\section{System CONFiguration AND CONTROL STRATEgy}

The main circuit of a STATCOM is shown in Fig. 1. $u_{k}(k=a, b, c)$ is the phase to neutral source voltage, $i_{L k}$ is the load phase current, $i_{s k}$ is the source phase current, $i_{c k}$ is the output phase current, and $U_{d c}$ is the DC side voltage. A singlephase equivalent circuit is shown in Fig. 2. The variables are shown as follows. $u_{s}$ is the source voltage, $u_{L}$ is the voltage of the inductor, $i_{c}$ is the output current, $u_{I}$ is the output voltage of the converter, and $Z(Z=j \omega L)$ is the impedance of the inductor. The losses of the converter are regarded as the active power in the resistor of the inductor [23]-[25].

The mathematical instantaneous three-phase model of a STATCOM is shown as (1) and (2). Using the transformation, equation (1) can be transformed to the synchronously rotating reference frame as (3). With (4) and (5), the STATCOM system model can be carried out as (6) [16], where $\delta$ is the phase angle between the source phase voltage and the output phase voltage of the converter. The variable $\theta$ is determined by the amplitude of the output voltage. The $\mathrm{d}$ axis in the reference frame has

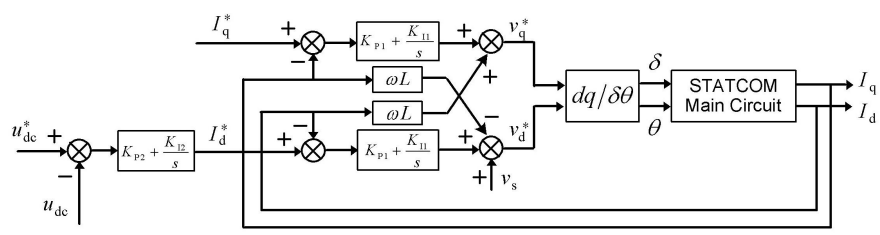

Fig. 3. Phase and amplitude control diagram of STATCOM.

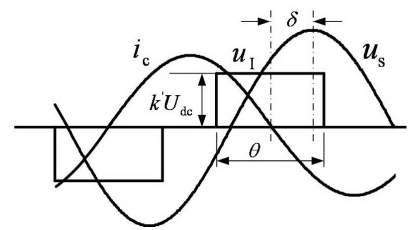

Fig. 4. Control principle of the STATCOM.

the same direction as the phasor of the source voltage, that is, the initial rotating angle is zero. The $\mathrm{q}$ axis is perpendicular to the $\mathrm{d}$ axis. Therefore, $u_{s q}=0$. The parameter $k$ is decided by the DC side voltage and the peak value of the output voltage.

$$
\begin{gathered}
L \frac{d}{d t}\left[\begin{array}{l}
i_{\mathrm{ca}} \\
i_{\mathrm{cb}} \\
i_{\mathrm{cc}}
\end{array}\right]+\left[\begin{array}{l}
R i_{\mathrm{ca}} \\
R i_{\mathrm{cb}} \\
R i_{\mathrm{cc}}
\end{array}\right]=\left[\begin{array}{l}
u_{\mathrm{Ia}} \\
u_{\mathrm{Ib}} \\
u_{\mathrm{Ic}}
\end{array}\right]-\left[\begin{array}{l}
u_{\mathrm{a}} \\
u_{\mathrm{b}} \\
u_{\mathrm{c}}
\end{array}\right] \\
\frac{d}{d t} u_{\mathrm{dc}}=-\frac{1}{C} i_{\mathrm{dc}} \\
\frac{d}{d t}\left[\begin{array}{l}
i_{\mathrm{d}} \\
i_{\mathrm{q}}
\end{array}\right]=\frac{1}{L}\left[\begin{array}{l}
u_{\mathrm{d}}-u_{\mathrm{sd}} \\
u_{\mathrm{q}}-u_{\mathrm{sq}}
\end{array}\right]-\left[\begin{array}{c}
\frac{R}{L_{\mathrm{d}}-\omega i_{\mathrm{q}}} \\
\frac{R}{L} i_{\mathrm{q}}+\omega i_{\mathrm{d}}
\end{array}\right] \\
\left.\frac{d}{d t}\left[\begin{array}{c}
i_{\mathrm{dc}} i_{\mathrm{dc}}=\frac{3}{2}\left(u_{\mathrm{d}} i_{\mathrm{d}}+u_{\mathrm{q}} i_{\mathrm{q}}\right) \\
i_{\mathrm{q}} \\
u_{\mathrm{dc}}
\end{array}\right]=\begin{array}{c}
u_{\mathrm{d}}=k u_{\mathrm{dc}} \cos \delta \\
-\frac{R}{L} \\
-\omega \\
-\frac{k}{2} k \cos \delta-\frac{3}{2 C} k \sin \delta \quad 0
\end{array}\right]\left[\begin{array}{l}
i_{\mathrm{d}} \\
i_{\mathrm{q}} \\
u_{\mathrm{dc}}
\end{array}\right]-\frac{1}{L}\left[\begin{array}{l}
u_{\mathrm{sd}} \\
0
\end{array}\right]
\end{gathered}
$$

A phase and amplitude control diagram of a STATCOM is shown in Fig. 3.

The control principle is shown in Fig. 4 [16], and several pulse waveforms can be used instead of rectangular waveforms in order to eliminate the harmonics when the fundamental part of output voltage is just guaranteed.

With the Fourier analysis, the fundamental part is expressed as (7). The relationship between $\delta / \theta$ and $u_{d} / u_{q}$ is expressed in (8) $[16]$.

$$
\begin{gathered}
\left\{\begin{array}{c}
u_{\mathrm{d}}=\frac{4}{\pi} u_{\mathrm{dc}} \sin \frac{\theta}{2} \cos \delta \\
u_{\mathrm{q}}=\frac{4}{\pi} u_{\mathrm{dc}} \sin \frac{\theta}{2} \sin \delta
\end{array}\right. \\
\left\{\begin{array}{l}
\theta=2 \arcsin \left(\frac{\pi}{4 u_{\mathrm{dc}}} \sqrt{u_{\mathrm{d}}^{2}+u_{\mathrm{q}}^{2}}\right) \\
\delta=\arctan \left(\frac{u_{\mathrm{q}}}{u_{\mathrm{d}}}\right)
\end{array}\right.
\end{gathered}
$$




\section{MOdel OF THE STATCOM SySTEM}

\section{A. Model of the main circuit}

By using (6), the main circuit model is expressed in (9). The small signal model is shown in (10). Where, the steady operation points are $u_{d c 0}, v_{d 0}, v_{q 0}, i_{d 0}$ and $i_{q 0}$, and $k=[4 \sin (\theta / 2)] / \pi$.

\section{B. Model of $d q / \delta \theta$}

The small signal model equations of $d q / \delta \theta$ are shown as (11) which were obtained by using equation (8).

\section{Model of the STATCOM System}

From (10) in A and (11) in B, the small signal model from the reference voltages to the output currents is carried out as (12). It is a model of the STATCOM system.

\section{Another modeling method}

Because the transfer function $d q / \delta \theta$ has no time delay and it is just a mathematical transfer function, the model from the reference voltages to the output currents can be presented directly by using (4). The small signal analysis is shown in (13). The same signal model can be obtained as (12). The two modeling methods have the same small signal model.

$u_{\mathrm{dc} 0} \frac{d\left(\Delta u_{\mathrm{dc}}\right)}{d t}=-\frac{3}{2 C}\left(u_{\mathrm{d} 0} \Delta i_{\mathrm{d}}+\Delta u_{\mathrm{d}} i_{\mathrm{d} 0}+u_{\mathrm{q} 0} \Delta i_{\mathrm{q}}+\Delta u_{\mathrm{q}} i_{\mathrm{q} 0}\right)$

\section{INFLUENCE OF THE PARAMETERS ON THE STATCOM System Characteristic AND Design Method}

There are two types of closed loops, one is the current loop, and the other is the DC voltage control loop. The designs of the two control loops and the influence of the main power parameters on STATCOM system stability are discussed. The designs of the parameters are also presented.

\section{A. Current control loop}

The current control loop is shown in Fig. 5. The two current loops are decoupled in Fig. 3. Because a period of the source current is used to calculate the rms of the current, the calculate part can be expressed as a first-order inertia element and a proportion model [26], [27]. The time delay is $T_{f} / 2\left(T_{f}\right.$ is the current period, 20ms).

When a proportion regulator is used, the transfer function of the current control loop is shown in (14).

$$
G_{\text {open }}(s)=\frac{k_{\mathrm{P} 1}}{\frac{L T_{\mathrm{f}}}{2} s^{2}+\left(\frac{R T_{\mathrm{f}}}{2}+L\right) s+R}
$$

A 50MVA $/ 10 \mathrm{kV}$ STATCOM is considered for analysis. In the traditional process, when the model of the STATCOM and the parameters are known, then a P regulator can be used to design a closed loop STATCOM system. However, the parameters of the interface inductor and the DC side capacitor, which are designed using many methods, are not precise enough. In the design process, a change in the interface inductor and the DC side capacitor is not convenient. Therefore, a proper parameter for the $\mathrm{P}$ regulator should be chosen, and the influences of the main circuit parameters on the STATCOM system should be analyzed. Then, it can provide a more optimized method to design the interface inductor and the DC side capacitor. An open loop Bode diagram and a closed loop Bode diagram are shown in Fig. 6 and Fig. 7, respectively. The current loop is stable. The cut-off frequency is approximately $10 \mathrm{~Hz}$, where $C=0.1 \mathrm{~F}, L=3 \mathrm{mH}, \omega=314, R=0.08 \Omega$, and $k_{p}=0.2$. The influence of STATCOM system parameters on the STATCOM system stability is presented in Fig. 8 and Fig. 9. From Fig. 8, parameter $R$ has a big influence on magnitudes of low frequency (below $2 \mathrm{~Hz}$ ). However, it does not have an influence on the magnitudes of medium and high frequency. When the resistor $R$ increases, magnitudes of low frequency decrease. From Fig. 9, parameter $L$ affects magnitudes of medium and high frequency. However, it does not have an affect on magnitudes of low frequency. When inductor $L$ increases, the cut-off frequency decreases and the effect on noise attenuation becomes better. Then, the phase margin of the STATCOM system increases. The relationship between the phase margin $\gamma$ and the inductor $L$ is illustrated in (15), where, $\omega_{0}$ is the crossing frequency, which can be obtained according to (16).

$$
\begin{gathered}
\gamma=180^{\circ}-\arctan \frac{\omega_{0} T_{\mathrm{f}}}{2}-\arctan \frac{\omega_{0} L}{R} \\
\frac{k_{\mathrm{P} 1}}{\left(1+\frac{T_{\mathrm{f}}}{2} \omega_{0}\right)\left(L \omega_{0}+R\right)}=1
\end{gathered}
$$

The phase margin $\gamma$, considered as one of input filter parameters, can be used to design the interface inductor. It is good for the stability and reliability of the whole STATCOM system. The interface inductor can be designed by using (17). The more the inductor increases, the bigger the phase margin becomes. An example is shown in Fig. 10 , where $k_{P 1}=0.2$, $L=5 \mathrm{mH}, R=0.08 \Omega$, and $C=80000 \mu \mathrm{F}$.

$$
L=\frac{R}{\omega_{0}} \tan \left(180^{\circ}-\arctan \frac{\omega_{0} T_{\mathrm{f}}}{2}-\gamma\right)
$$

When the regulator is a PI regulator, the same conclusions are obtained. This is because the integration part increases magnitudes of low frequency and only affects the low frequency part in the open loop Bode diagram.

\section{B. DC side voltage control loop}

The DC side voltage control loop is shown in Fig. 11. From (12), the transfer functions can be presented as (18). The relationships between the variables in the synchronously rotating reference frame and the variables in the stationary reference frame ( $a b c$ frame) are shown in (19) and (20), where $E_{m}$ is the peak value of the source voltage in the $a b c$ frame and $I_{m}$ is the peak value of the active current in the $a b c$ frame. Then, the small signal model is expressed as equation (21).

$$
\left\{\begin{aligned}
\frac{\Delta u_{\mathrm{dc}}}{\Delta i_{\mathrm{d}}} & =\frac{-\frac{3}{2 C u_{\mathrm{dc} 0}}\left(L i_{\mathrm{d} 0} s+u_{\mathrm{sd} 0}+2 R i_{\mathrm{d} 0}\right)}{s} \\
\frac{\Delta u_{\mathrm{dc}}}{\Delta i_{\mathrm{q}}} & =\frac{-\frac{3}{2 C u_{\mathrm{dc} 0}}\left(L i_{\mathrm{q} 0} s+u_{\mathrm{sq} 0}+2 R i_{\mathrm{q} 0}\right)}{s}
\end{aligned}\right.
$$




$$
\begin{aligned}
& \frac{d}{d t}\left[\begin{array}{l}
i_{\mathrm{d}} \\
i_{\mathrm{q}} \\
u_{\mathrm{dc}}
\end{array}\right]=\left[\begin{array}{ccc}
-\frac{R}{L} & \omega & \frac{4}{\pi L} \sin \frac{\theta}{2} \cos \delta \\
-\omega & \frac{-R}{L} & \frac{4}{\pi L} \sin \frac{\theta}{2} \sin \delta \\
-\frac{6}{C \pi} \sin \frac{\theta}{2} \cos \delta & -\frac{6}{C \pi} \sin \frac{\theta}{2} \sin \delta & 0
\end{array}\right]\left[\begin{array}{l}
i_{\mathrm{d}} \\
i_{\mathrm{q}} \\
u_{\mathrm{dc}}
\end{array}\right]-\frac{1}{L}\left[\begin{array}{l}
u_{\mathrm{sd}} \\
0
\end{array}\right] \\
& \frac{d}{d t}\left[\begin{array}{c}
\Delta i_{d} \\
\Delta i_{q} \\
\Delta u_{d c}
\end{array}\right]=\left[\begin{array}{ccc}
-\frac{R}{L} & \omega & \frac{4}{\pi L} \sin \frac{\theta_{0}}{2} \cos \delta_{0} \\
-\omega & -\frac{R}{L} & \frac{4}{\pi L} \sin \frac{\theta_{0}}{2} \sin \delta_{0} \\
-\frac{6}{\pi C} \sin \frac{\theta_{0}}{2} \cos \delta_{0} & -\frac{6}{\pi C} \sin \frac{\theta_{0}}{2} \sin \delta_{0} & 0
\end{array}\right]\left[\begin{array}{c}
\Delta i_{d} \\
\Delta i_{q} \\
\Delta u_{d c}
\end{array}\right]+ \\
& {\left[\begin{array}{cc}
-\frac{4}{\pi L} u_{\mathrm{dc} 0} \sin \frac{\theta_{0}}{2} \sin \delta_{0} & \frac{2}{\pi L} u_{\mathrm{dc} 0} \cos \frac{\theta_{0}}{2} \cos \delta_{0} \\
\frac{4}{\pi L} u_{\mathrm{dc} 0} \sin \frac{\theta_{0}}{2} \cos \delta_{0} & \frac{2}{\pi L} u_{\mathrm{dc} 0} \cos \frac{\theta_{0}}{2} \sin \delta_{0} \\
\frac{3}{\pi C} \sin \frac{\theta_{0}}{2}\left(i_{\mathrm{d} 0} \sin \delta_{0}-i_{\mathrm{q} 0} \cos \delta_{0}\right) & -\frac{3}{\pi C} \cos \frac{\theta_{0}}{2}\left(i_{d 0} \cos \delta_{0}+i_{\mathrm{q} 0} \sin \delta_{0}\right)
\end{array}\right]\left[\begin{array}{c}
\Delta \delta \\
\Delta \theta
\end{array}\right]} \\
& \left\{\begin{array}{l}
\Delta \delta=-\frac{\pi}{4 u_{\mathrm{dc} 0} \sin \frac{\theta_{0}}{2}} \sin \delta_{0} \Delta u_{\mathrm{d}}+\frac{\pi}{4 u_{\mathrm{dc} 0} \sin \frac{\theta_{0}}{2}} \cos \delta_{0} \Delta u_{\mathrm{q}} \\
\Delta \theta=2 \frac{\pi}{4 u_{\mathrm{dc} 0} \cos \frac{\theta_{0}}{2}} \cos \delta_{0} \Delta u_{\mathrm{d}}+2 \frac{\pi}{4 u_{\mathrm{dc} 0} \cos \frac{\theta_{0}}{2}} \sin \delta_{0} \Delta u_{\mathrm{q}}-\frac{2 \Delta u_{\mathrm{dc}} \sin \frac{\theta_{0}}{2}}{u_{\mathrm{dc} 0} \cos \frac{\theta_{0}}{2}}
\end{array}\right.
\end{aligned}
$$

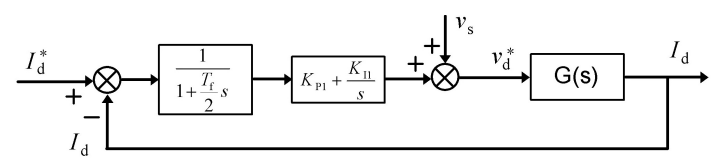

Fig. 5. Current control loop of the STATCOM.

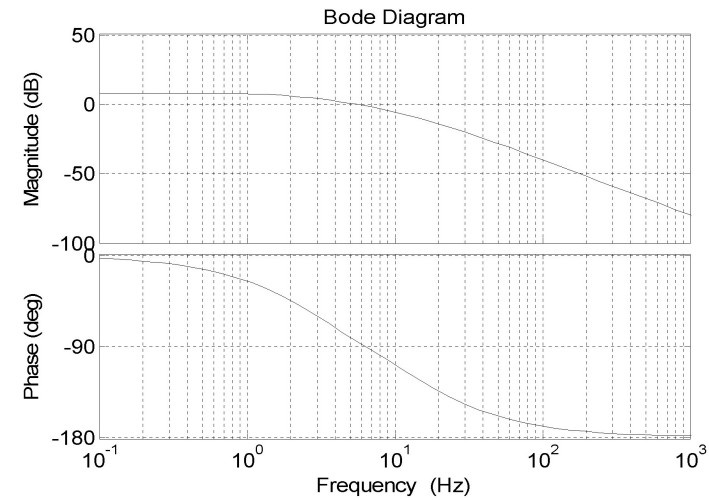

Fig. 6. Bode diagram of the open loop.

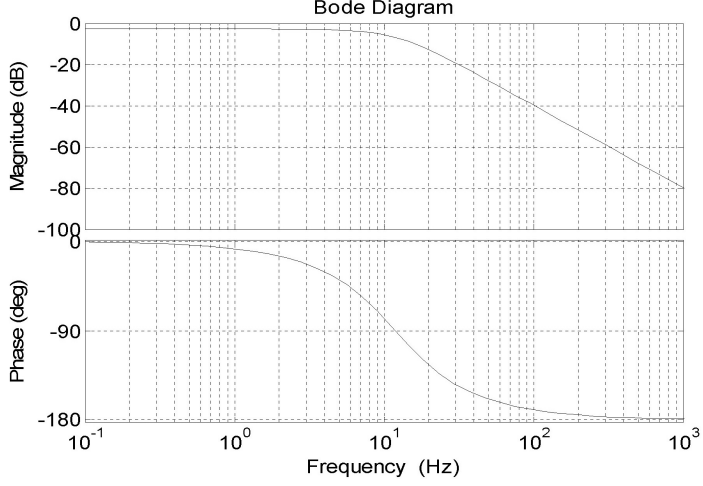

Fig. 7. Bode diagram of the closed loop.

$$
\begin{aligned}
& u_{\mathrm{d} 0}=\sqrt{3} \sqrt{\frac{2}{3}} U_{\mathrm{sa}}=E_{\mathrm{m}} \\
& i_{\mathrm{d} 0}=\sqrt{3} \sqrt{\frac{2}{3}} I_{\mathrm{a}}=I_{\mathrm{m}} \\
& \frac{\Delta u_{\mathrm{dc}}}{\Delta i_{\mathrm{d}}^{*}}=-\frac{\frac{3 k_{\mathrm{P} 1}}{2 C u_{\mathrm{dc} 0}}\left(E_{\mathrm{m}}+2 R I_{\mathrm{m}}+L I_{\mathrm{m}} s\right)}{s\left(\frac{L T_{\mathrm{f}}}{2} s^{2}+\left(\frac{R T_{\mathrm{f}}}{2}+L\right) s+R+k_{\mathrm{P} 1}\right)}
\end{aligned}
$$




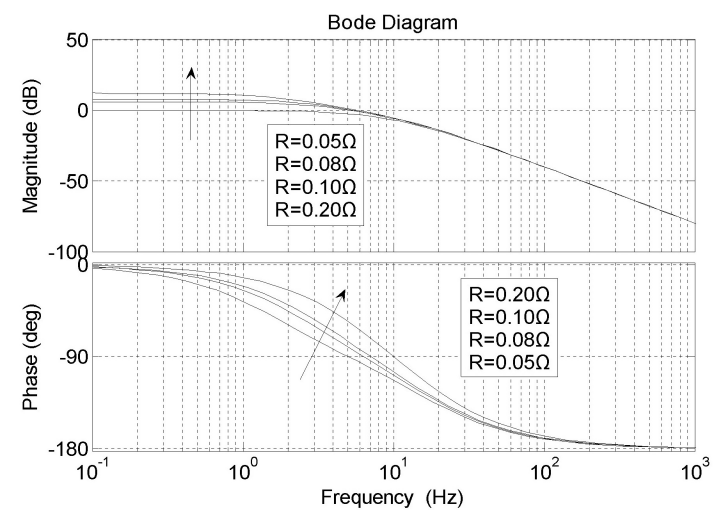

Fig. 8. Influence of $R$ on the open loop.

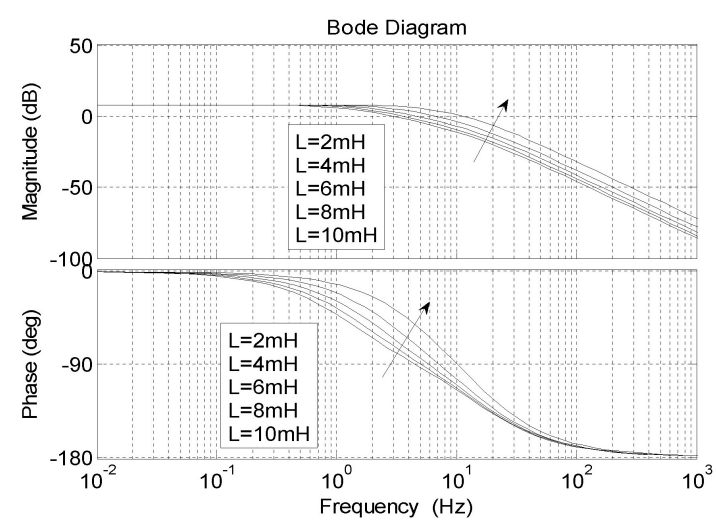

Fig. 9. Influence of $L$ on the open loop.

Because the cut-off frequency of the DC side voltage control loop is much larger than that of the current control loop, the magnitude of the current control loop can be considered as one. The open loop transfer function of the DC side voltage control loop is shown in (22).

$$
G_{\mathrm{V}}(s)=k_{\mathrm{P} 2} \frac{\Delta u_{\mathrm{dc}}}{\Delta i_{\mathrm{d}}^{*}}=\frac{\frac{3 k_{\mathrm{P} 1} k_{\mathrm{P} 2}}{2 C u_{\mathrm{dc} 0}}\left(E_{\mathrm{m}}+2 R I_{\mathrm{m}}+L I_{\mathrm{m}} s\right)}{s}
$$

Bode diagrams of the DC side voltage control's open loop and closed loop are shown in Fig. 12 and Fig. 13. The cut-off frequency is approximately $0.6 \mathrm{~Hz}$, where $k_{P 1}=0.2$, $k_{P 2}=1, L=5 \mathrm{mH}, R=0.08 \Omega, C=0.1 \mathrm{~F}, E_{m}=8164 \mathrm{~V}, I_{m}=-164 \mathrm{~A}$, and $u_{d c 0}=2.5 \mathrm{kV}$.

From Fig. 14, there is a Right-half Plane Zero. However, the Right-half Plane Zero is very large and it has a small influence on the STATCOM system stability. The influence of the STATCOM system parameter $C$ on the STATCOM system stability is presented in Fig. 15. From Fig. 15, it can be seen that parameter $C$ has a large influence on the magnitude characteristic, and that it does not affect the phase characteristic. When capacitor $C$ increases, the cut-off frequency decreases, and the effect on noise attenuation becomes better. The phase margin of the STATCOM system increases.

When the regulator is a PI regulator, the same conclusions are obtained. This is due to the fact that the integration part affects the low frequency.

The relationship between the phase margin $\gamma$ and the DC side capacitor $C$ is illustrated in (23), where $\omega_{0}$ is the crossing

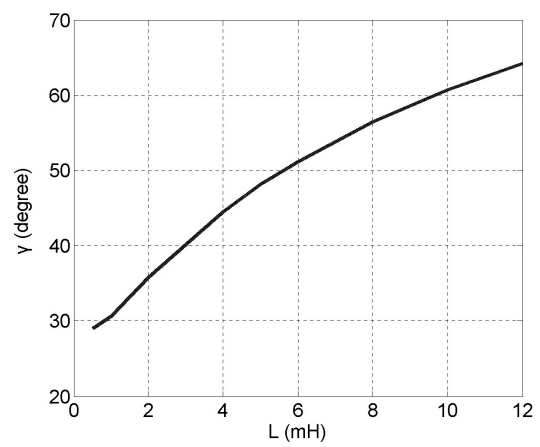

Fig. 10. Relationship between phase margin $\gamma$ and interface inductor $L$.

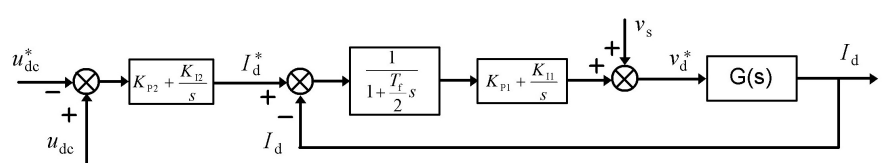

Fig. 11. DC side voltage control loop of the STATCOM.

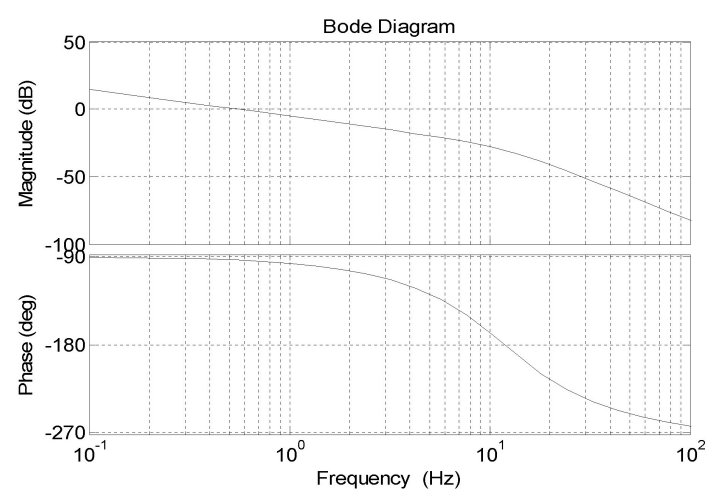

Fig. 12. Bode diagram of the open loop.

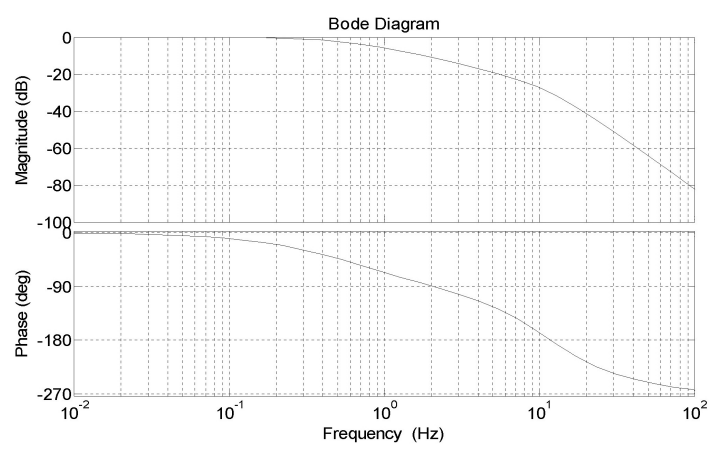

Fig. 13. Bode diagram of the closed loop.

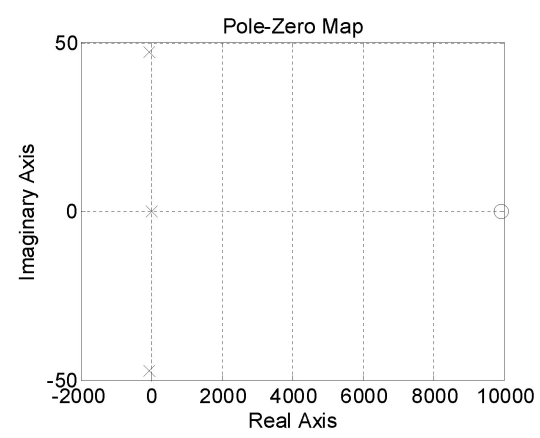

Fig. 14. Pole-zero map of open loop. 


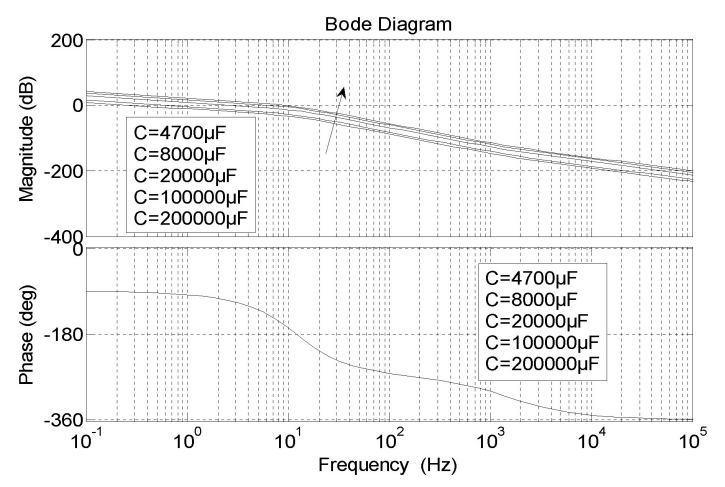

Fig. 15. Influence of $C$ on the open loop.

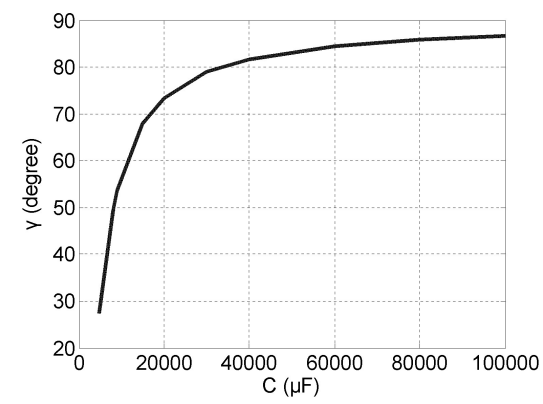

Fig. 16. Relationship between phase margin $\gamma$ and capacitor $C$.

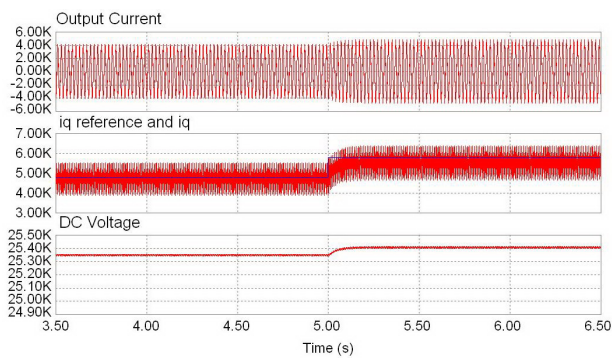

Fig. 17. Current step response at $5 \mathrm{~s}$.

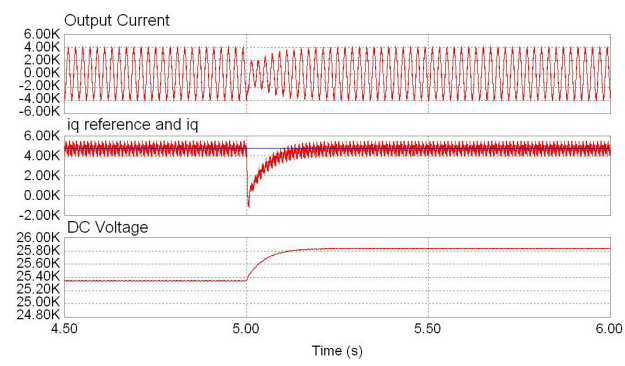

Fig. 18. DC side voltage step response at $5 \mathrm{~s}$.

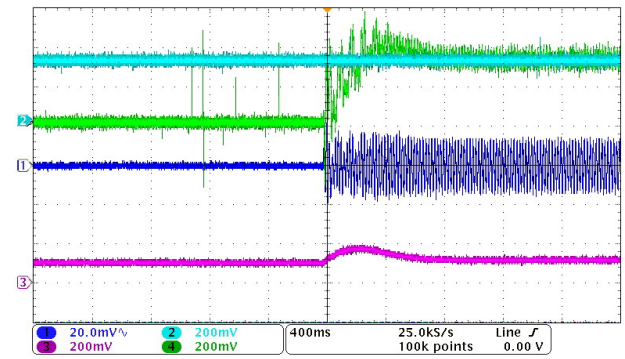

Fig. 19. Current response of dynamic process. Ch1:output current in $a b c$ frame; $\mathrm{Ch} 2$ :reference current in synchronously rotating reference frame; $\mathrm{Ch} 3$ : DC side voltage; Ch4:output current in synchronously rotating reference frame.

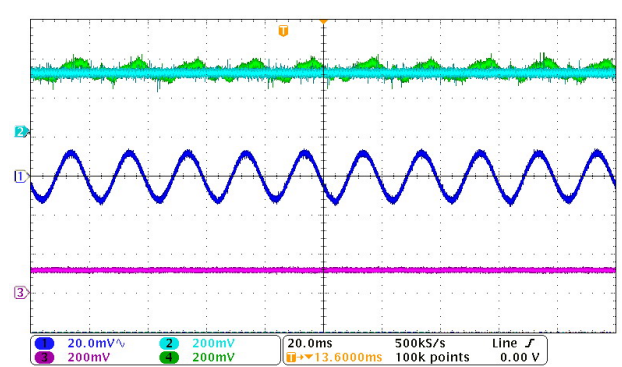

Fig. 20. Current response of stead-state. Ch1:output current in $a b c$ frame; Ch2:reference current in synchronously rotating reference frame; Ch3: DC side voltage; Ch4:output current in synchronously rotating reference frame.
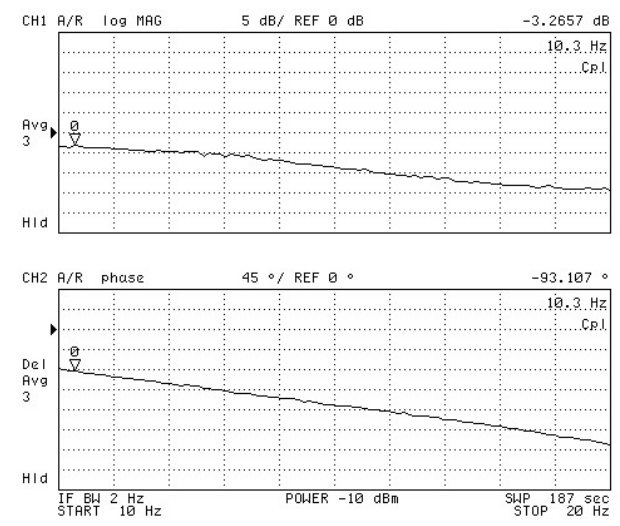

Fig. 21. Bode diagram of current control loop.

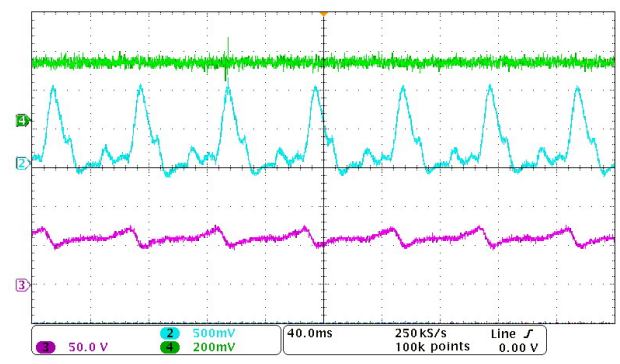

Fig. 22. Unstable current control loop. $L=2.2 \mathrm{mH}$, Ch2:reference current in synchronously rotating reference frame; Ch3: DC side voltage; Ch4:output current in synchronously rotating reference frame.

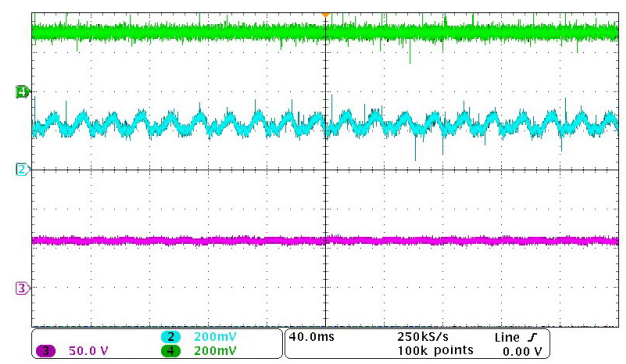

Fig. 23. Stable current control loop. $L=5.5 \mathrm{mH}, \mathrm{Ch} 2$ :reference current in synchronously rotating reference frame; Ch3: DC side voltage; Ch4:output current in synchronously rotating reference frame. 


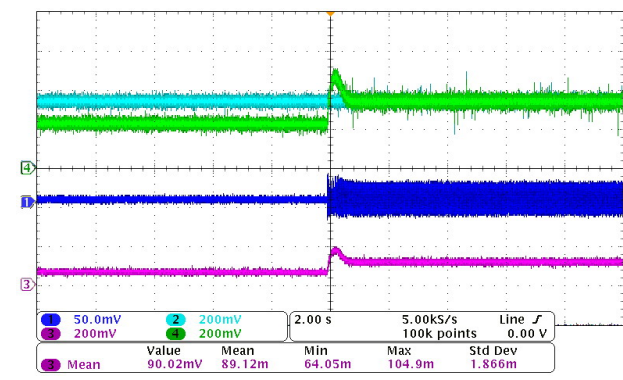

Fig. 24. DC side voltage response of dynamic process. Ch1:output current in $a b c$ frame; Ch2:reference voltage in synchronously rotating reference frame; Ch3: DC side voltage; Ch4:DC side voltage in synchronously rotating reference frame.

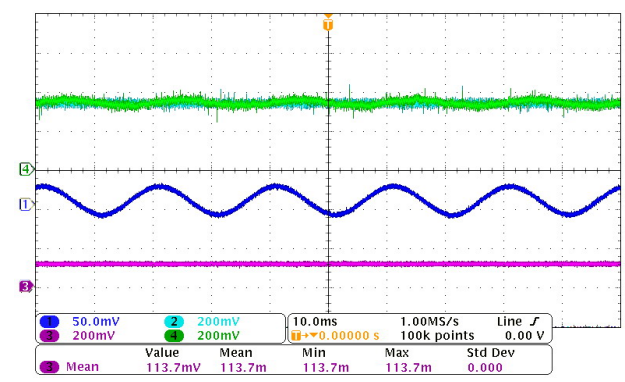

Fig. 25. DC side voltage response of stead-state. Ch1:output current in $a b c$ frame; Ch2:reference voltage in synchronously rotating reference frame; Ch3: DC side voltage; Ch4:DC side voltage in synchronously rotating reference frame. frequency, and it can be obtained according to (24).

$$
\begin{gathered}
\gamma=90^{\circ}+\arctan \frac{\omega_{0} L I_{\mathrm{m}}}{E_{\mathrm{m}}+2 R I_{\mathrm{m}}} \\
\omega_{0}=\frac{3 k_{\mathrm{P} 2}}{2 C u_{d c 0}} E_{\mathrm{m}} / \sqrt{1-\left(\frac{3 k_{\mathrm{P} 2}}{2 C u_{\mathrm{dc} 0}} L I_{\mathrm{m}}\right)^{2}}
\end{gathered}
$$

The phase margin $\gamma$ considered as one of the variables can be used to design the capacitor. It is good for the stability and reliably of the whole STATCOM system. The capacitor can be designed by using (25). The more the capacitor increases, the bigger the phase margin is. An example is shown in Fig. 16, where $k_{P 1}=0.2, k_{P 2}=0.8, L=5 \mathrm{mH}, R=0.08 \Omega, E_{m}=8164 \mathrm{~V}$, and $I_{m}=-164 \mathrm{~A}$.

$$
C \approx \frac{3 k_{\mathrm{P} 2} \sqrt{1+\tan ^{2}\left(\gamma-90^{\circ}\right)}}{2 u_{d c 0} \tan \left(\gamma-90^{\circ}\right)}
$$

\section{Simulation ANd Experimental REsults}

In order to verify the analysis and specifications, simulation and hardware experimental investigations were carried out. The current response and the DC side voltage response are shown in Fig. 17 and Fig. 18. From the simulation results, the analysis of the model of is verified.

The low voltage hardware experiment is presented in Fig. 19 to Fig. 27. In terms of the current control loop, in Fig. 19 and Fig. 20, the output current can track the reference current. In order to verify the current loop model, in the experiment, an Agilent 4395A Network/Spectrum/Impedance Analyzer was used to analyze the current control loop, in Fig. 21 . The lowest frequency of the equipment is $10 \mathrm{~Hz}$. However, the cut-off frequency could be read, and it was approximately $10 \mathrm{~Hz}$. There was a time delay of 37 degrees because of the calculation time. The experimental result verified the analysis of the current control loop.

Fig. 22 and Fig. 23 verify (15). When the interface inductor was $2.2 \mathrm{mH}$, the STATCOM system was unstable and the output current oscillated. When the interface inductor was increased to $5.5 \mathrm{mH}$, the STATCOM system was stable. It verified the conclusion in (15), that the more the inductor is increased, the bigger the phase margin becomes.

In terms of the DC side voltage control loop, from Fig. 24 and Fig. 25, the DC side voltage can track the reference voltage. The experimental result verified the analysis of the DC side voltage control loop.

Fig. 26 and Fig. 27 verify (23). When the DC side capacitor was $3333 \mu \mathrm{F}$, the STATCOM system was unstable and the voltage oscillated. When the DC side capacitor was increased to $6666 \mu \mathrm{F}$, the STATCOM system was stable. It verified the conclusion in (23), that the more the DC side capacitor is increased, the bigger the phase margin becomes.

\section{CONCLUSIONS}

In this paper, a model of the phase and amplitude control is presented. A detailed analysis of the influences of the interface inductor and the DC side capacitor on the STATCOM systems and the corresponding design considerations are presented. The influences of the interface inductor and the DC side 
capacitor on the STATCOM system stability and filtering characteristics are extensively investigated. A method based on the phase margin to design the interface inductor and the DC side capacitor is presented in this paper.

\section{ACKNOWLEDGMENT}

This work was sponsored by "the Fundamental Research Funds for the Central Universities".

\section{REFERENCES}

[1] N. G. Hingorani, L. Gyugyi, Understanding FACTS-Concepts and Technology of Flexible AC Transmission Systems. New York: IEEE Press, pp. 10-13, 1999.

[2] H. M. Pirouz and M. T. Bina, "Modular multilevel converter based statcom topology suitable for medium-voltage unbalanced systems," Journal of Power Electronics, Vol. 10, No. 5, pp. 572-578, Sep. 2010.

[3] C.-K. Kim, V. Sood, and S.-J. Lee, "Dynamic coordination strategies between HVDC and STATCOM," Journal of Power Electronics, Vol. 9, No. 6, pp. 892-902, Sep. 2009.

[4] B. Singh, P. Jayaprakash, and D. P. Kothari, "A three-phase four-wire dstatcom for power quality improvement," Journal of Power Electronics, Vol. 8, No. 3, pp. 259-267, Jul. 2008.

[5] B. Singh and J. Solanki, "An improved control approach for dstatcom with distorted and unbalanced ac mains," Journal of Power Electronics, Vol. 8, No. 2, pp. 131-140, Apr. 2008.

[6] B. Singh and R. Saha, "Modeling of 18-pulse STATCOM for power system applications," Journal of Power Electronics, Vol. 7, No. 2, pp. 146-158, Apr. 2007.

[7] T. C. Y. Wang, Z. Ye, G. Sinha, and X. Yuan, "Output filter design for a grid-interconnected three-phase inverter," in Proc. of IEEE 34th Annual Power Electronics Specialist Conf., Vol. 2, pp. 779-784, Jun. 2003.

[8] Y. Lang, D. Xu, S. R. Hadianamrei, and H. Ma, "A novel design method of lcl type utility interface for three-phase voltage source rectifier," in Proc. of IEEE 36th Power Electronics Specialists Conf., pp. 313-317, Jun. 2005.

[9] L. Yiqiao and C. O. Nwankpa, "A new type of STATCOM based on cascading voltage-source inverters with phase-shifted unipolar SPWM," IEEE Trans. Ind. Appl., Vol. 35, No. 5, pp. 1118-1123, Sep./Oct. 1999.

[10] J. G. Hwang, P. W. Lehn, and M. Winkelnkemper, "Control of grid connected AC-DC converters with minimized DC link capacitance under unbalanced grid voltage condition," in Proc. of Power Electronics and Applications European Conf., pp. 1-10, 2007.

[11] J. Hobraiche, J. P. Vilain, and C. Plasse, "Offline optimized pulse pattern with a view to reducing DC-link capacitor application to a starter generator," in Proc. of 2004 IEEE 35th Annual Power Electronics Specialists Conf., Vol. 5, pp. 3336-3341, 2004.

[12] B. G. Gu and K. Nam, "A Theoretical minimum DC-link capacitance in PWM converter-inverter systems," IEE Proceedings Electric Power Applications, Vol. 152, No. 1, pp. 81-88, Jan. 2005.

[13] B.-G. Gu and K. Nam, "A DC-link capacitor minimization method through direct capacitor current control," IEEE Trans. Ind. Appl., Vol. 42, No. 2, pp. 573-581, Mar./Apr. 2006.

[14] A. Kotsopoulos, J. L. Duarte, and M. A. M Hendrix, "A predictive control scheme for DC voltage and AC current in grid-connected photovoltaic inverters with minimum DC link capacitance," in Proc. of 2001 IEEE Industrial Electronics Society 27th Annual Conf., Vol. 3, pp. 1994-1999, 2001.

[15] C.-T. Pan and J.-J. Shieh, "New space-vector control strategies for three-phase step-up/down AC/DC converter," IEEE Trans. Ind. Electron., Vol.47, No. 1, pp. 25-35, Feb. 2000.

[16] M. Liserre, F. Blaabjerg, and S. Hansen, "Design and control of an LCLfilter-based three-phase active rectifier," IEEE Trans. Ind. Appl., Vol. 41, No. 5, pp. 1281-1291, Sep./Oct. 2005.

[17] C. Schauder, "Vector analysis and control of advanced static VAr compensators," in Proc. of 1991 IEEE AC and DC Power Transmission International Conf., pp. 266-272, Sep. 1991.

[18] B. M. Han, G. G. Karady, J. K. Park, and S. I. Moon, "Interaction analysis model for transmission static compensator with EMTP," IEEE Trans. Power Del., Vol. 13, No. 4, pp. 1297-1302, Oct. 1998.

[19] K. R. Padiyar, A. M. Kulkarni, "Analysis and design of voltage control of static condenser," in Proc. of 1996 Power Electronics, Drives and Energy Systems for Industrial Growth International Conference, Vol. 1, pp. 393-398, 1996.
[20] J. B. Choo, J. S. Yoon, B. H. Chang, B. Han, and K. K. Koh, "Development of FACTS operation technology to the KEPCO power network-detailed EMTDC model of 80 MVA UPFC," in Proc. of 2002 IEEE Transmission and Distribution Conference and Exhibition 2002: Asia Pacific, Vol. 1, pp. 354-358, Oct. 2002.

[21] Z. Yang, C. Shen, L. Zhang, M. L. Crow, and S. Atcitty, "Integration of a StatCom and battery energy storage," IEEE Trans. Power Syst., Vol. 16, No. 2, pp. 254-260, May 2001.

[22] L. Dong, M. L. Crow, Z. Yang, C. Shen, L. Zhang, and S. Atcitty, "A reconfigurable FACTS system for university laboratories," IEEE Trans. Power Syst., Vol. 19, No. 1, pp. 120-128, Feb. 2004.

[23] J. W. Kolar, F. C. Zach, and F. Casanellas, "Losses in PWM inverters using IGBTs," IEE Proceedings Electric Power Applications, Vol. 142, No. 4, pp. 285-288, Jul. 1995.

[24] B. T. Ooi, G. Joos, and X. Huang, "Operating principles of shunt STATCOM based on 3-level diode-clamped converters," IEEE Trans. Power Del., Vol. 14, No. 4, pp. 1504-1510, Oct. 1999.

[25] D. Shen, X. Liang, and Y. Han, "A modified per-unit STATCOM model and analysis of open loop response time," in Proc. of 2000 IEEE Power Engineering Society Winter Meeting, Vol. 4, pp. 2624-2629, Jan. 2000.

[26] Y. Jiang and A. Ekstrom, "Applying PWM to control overcurrents at unbalanced faults of forced-commutated VSCs used as static VAr compensators," IEEE Trans. Power Del., Vol. 12, No. 1, pp. 273-278, Jan. 1997.

[27] V. Blasko and V. Kaura, "A new mathematical model and control of a three-phase AC-DC voltage source converter," IEEE Trans. Power Electron., Vol. 12, No. 1, pp. 116-123, Jan. 1997.

[28] V. Blasko and V. Kaura, "A novel control to actively damp resonance in input LC filter of a three-phase voltage source converter," IEEE Trans. Ind. Appl., Vol. 33, No. 2, pp. 542-550, Mar./Apr. 1997.

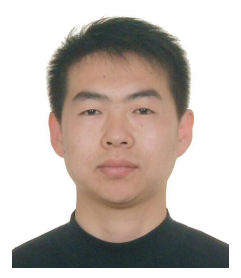

Guopeng Zhao was born in Inner Mongolia Province, China in 1980. He received his B.S. from Northwestern Polytechnical University, China, in 2003. He received his M.S. and Ph.D. from Xi'an Jiaotong University (XJTU), China, in 2006 and 2010, respectively, both in Electrical Engineering. He is currently a Lectorate of the North China Electric Power University. His current research interests include power quality control and the application of power electronics in power systems.

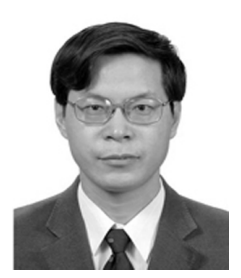

Minxiao Han was born in Shaanxi Province, China, in 1963. He received his B.S. from Xi'an Jiaotong University, in 1984, and his M.S. and Ph.D. from the North China Electric Power University (NCEPU), in 1987 and 1995, respectively. He was a Visiting Research Fellow at the Queen's University of Belfast, U.K. and a Post Doctoral Research Fellow at Kobe University, Japan. He is active in professional society activities and international cooperation relating to research on the application of power electronics in power systems including HVDC and FACTS, power quality and the integration of renewable energy generation into the power network.

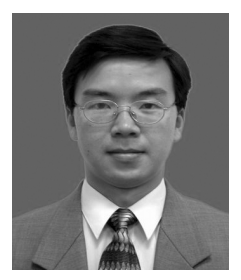

Jinjun Liu was born in Hunan Province, China, in 1970. He received his B.S. and Ph.D. from Xi'an Jiaotong University (XJTU), China, in 1992 and 1997, respectively. In 1998, he led the founding of the XJTU/Rockwell Automation Laboratory. From December 1999 until February 2002, he was with the Center for Power Electronics Systems at the Virginia Polytechnic Institute and State University, USA, as a Postdoctoral Research Scholar. He then returned to XJTU and in August of 2002 was promoted to a Full Professor and head of the Power Electronics and Renewable Energy Center at XJTU. He is currently serving as an Associate Dean of the School of Electrical Engineering at XJTU. He has coauthored 3 books, published over 100 technical papers, and received several provincial or ministerial awards for scientific and career achievements. He also received the 2006 Delta Scholar Award. His current research interests include power quality control, renewable energy generation, utility application of power electronics, and the modeling and control of power electronic systems. Dr. Liu has served as the IEEE Power Electronics Society Region 10 Liaison for 3 years. He has been actively involved in the organization of several power electronic international conferences, including PESC, APEC, IPEC, in Japan, ICPE, in Korea, and IPEMC, in China, as a committee member, co-chair, or session chair. 